\title{
CYTOCHROME OXIDASE SUBUNIT AND INTERNAL TRANSCRIBED SPACER MOLECULAR REVELATION OF INFECTION WITH FASCIOLA SP. IN FIELD- COLLECTED LYMNAEA NATALENSIS SNAILS
}

\author{
By \\ AMINA M. IBRAHIM ${ }^{1}$ AND SAMI M. NASR ${ }^{2}$ \\ Departments of Environmental Research and Medical Malacology ${ }^{1}$ and Biochemistry, \\ Molecular Biology and Medicinal Chemistry ${ }^{2}$, Theodor Bilharz Research Institute, \\ Imbaba P.O.B. 30. Giza, Egypt ( ${ }^{*}$ Correspondence: aminamd.ibrahim@yahoo.com) \\ Abstract
}

Fasciolosis is one of the neglected tropical diseases that negatively affect the farming industry and public health. The present study aimed to evaluate a polymerase chain reaction (PCR) assay for detection of infection with Fasciola sp. in field-collected Lymnaea natalensis snails from two rural localities in Egypt; and to compare between it and the ordinary microscopic methods. A total of 1000 lymnaeid snails were collected, and then the samples were examined for the infection by crushing, cercarial shedding and molecular methods. The average sensitivity of microscopic methods compared to PCR was $56.15 \%$ and this gives the indication that the molecular techniques were highly sensitive, specific and reliable methods for detecting Fasciola $s p$. The study detected two genes; nuclear ribosomal central internal transcribed spacer 1 (ITS1856bp) and mitochondrial cytochrome oxidase subunit I (CO1 831bp). Gel electrophoresis showed strong bands for these single snails' samples and confirmed the presence of infection in both localities. Molecular techniques gave sensitive, accurate identification of infection, established prevalence in endemic areas and planning time for proper control strategy.

Keywords: Fasciolosis; Lymnaea natalensis; Microscopic methods; PCR; ITS1; CO1.

\section{Introduction}

Fasciolosis is a globally distributed helminthes infection of ruminants in tropical countries (Alba et al, 2015; WHO, 2017), caused by infection of trematodes belonging to the genus Fasciola sp. (Lotfy and Hillyer, 2003); Fasciola hepatica causes huge losses in sheep and cattle worldwide (Beesley et al, 2017) and human can get the infection accidentally from contaminated water or plants in endemic areas, where, millions of people are infected with fascioliasis around the world and there are more than 180 million at risk (Khan et al, 2017). Freshwater snails of the family Lymnaeidae serve as intermediate hosts in the transmission of these liver flukes (Yakhchali et al, 2015). L. natalensis snails were the main host for Fasciola hepatica or gigantica, which are widely distributed in Africa (Moema et al, 2008). These snails have a wide prevalence and distribution in nearly all the Egyptian Governorates (Ashour et al, 2008).

In Egypt, liver flukes of Fasciola sp. have negatively affected the farming industry and public health (Hussein and Khalifa, 2010), and both Fasciola hepatica and F. gigantica are present (Hussein and Khalifa, 2010; Dar et al, 2012). They cause economic losses of about US\$ 29.2 million annually (Arafa et $a l, 2018)$. Also, human infection is a major public health problem in several areas of the world, including the Nile Delta where 4\% were $F$. hepatica patients (Soliman, 2008).

To detect Fasciola sp. in field-collected snails, several techniques were used (Caron et al, 2014). Simplest method was snail crushing then dissection (Dreyfuss et al, 2005; Caron et al, 2008), but this method detected only live free rediae and free cercariae within the snail's haemocoel. Also, cercarial shedding method detected larval stages in the intermediate host (Kaplan et al, 1997; Baran et al, 2017). This technique has low sensitivity, specificity and was time-consuming (Caron et al, 2007). Both methods did not detect infection in the pre-patent period, compromising field trials (Magalhã-es et al, 2004). So, studies on natural infections of field-collected snails have employed molecular tools (Lotfy et al, 2008; Caron et al, 2014; Yakhchali et al, 2015). Molecular 
techniques are highly sensitive and specific methods in detecting these liver flukes in the snails faster and more accurate species identification (Kaplan et al, 1995). In Egypt $F$. hepatica \& F. gigantica intermediate snails were morphologically proved (Periago et al, 2008) and molecularly based on presence of ribosomal and mitochondrial genes (Amer et al, 2011; Dar et al, 2012). The nucleotide sequences of nuclear ribosomal central internal transcribed spacer1(ITS1), (ITS2) (Ichikawa and Itagaki, 2010) and DNA sequences of mitochondrial cytochrome oxidase subunit I (CO1) genes (Itagaki et al, 2005; Mas-Coma et al, 2009) identified Fasciola spp. (Zarowiecki et al, 2007).

Cytochrome oxidase enzyme fractional monetary unit considered as a factor typically used as a deoxyribonucleic acid barcode to spot animal species (Hebert et al, 2003). $\mathrm{CO} 1$ factor sequence is appropriate for this role as a result of its mutation rate which is usually quick enough to differentiate closely connected species. Internal transcribed spacers (ITS) refers to the spacer deoxyribonucleic acid set between the small-subunit ribosomal ribonucleic acid (rRNA) and largesubunit rRNA genes and contemplate because it is the most generally sequenced deoxyribonucleic acid region in molecular ecology (Ichikawa and Itagaki, 2010). Owing to its higher degree of variation than alternative sequence regions of rDNA, variation among individual rDNA repeats typical determination among ITS regions.

The present study aimed to compare between microscopy (shedding and crushing) and the conventional PCR to detect Fasciola infection in the field-collected L. natalensis snails from two rural localities in Giza governorate, Egypt.

\section{Materials and Methods}

The field groups included 1000 L. natalensis snails collected during March to September 2017, from different irrigation canals in two rural localities in Giza governorate (Abo-Rawash and Manshaat Radwan) every single snail in a clean screw capped tube.
The collection area covering one square meter through the agricultural canals. Snails found under water Lemna gibba leaves were collected manually by sweeping net. Lymnaeid snails were found in areas where water was stagnant or presented only a slow current, usually in places where livestock was present. The collected snails were transported to the lab at Theodor Bilharz research institute at the same day of collection. In Malacology laboratory, the snails were maintained in $60 \times 30 \times 30 \mathrm{~cm}$ plastic containers. Lymnaea snails were fed by lettuce 1-2 times per week and water in the containers was changed once 24-48 hrs. Eggs were collected daily on transparent plastic sheets placed into the aquaria.

Snail's infection: Two methods were carried out either, by exposure of snails to artificial light for one hr., at $25^{\circ} \mathrm{C}$, for cercarial shedding (Liang et al, 1987) or by crushing (Chu and Dawood, 1970), where, snails were crushed between two slides, and were carefully investigated under the dissection microscope. The collected cercariae were identified as fresh or stained samples with iodine solution using light microscope. Nonshedding snails were kept in the laboratory and re-examined weekly to verify that cercariae were not shed by snails which could have been infected only shortly before being collected. When snails proved to be negative after several examinations by the shedding method, they were gently crushed in a Petri dish containing a small amount of dechlorinated water.

Molecular detection by purification of genomic DNA from snails' tissues using a spin column technique: Soft tissue of $L$. natalensis single snail sample was dissected separately, washed in $0.01 \mathrm{M}$ phosphate- buffered saline (PBS, pH 7.2) and stored at $-20^{\circ} \mathrm{C}$. Genomic DNA was extracted by Wizard SV Genomic DNA Purification System cat. A2360 Promega. $275 \mu 1$ were added of the digestion solution master mix to each sample tube and the sample was completely covered. Sample tubes were incubated over- 
night (16-18hrs) in a $55^{\circ} \mathrm{C}$ heat block or water bath and $250 \mu \mathrm{l}$ of Wizard SV Lysis Buffer mixed to each sample by vortex. Entire sample lysate were transferred from $1.5 \mathrm{ml}$ microcentrifuge tube to a Wizard SV minicolumn assembly and spin at $13,000 \times \mathrm{g}$ for 3 minutes to bind the genomic DNA to the Wizard mini-column. The collected liquid was discarded and $650 \mu 1$ ethanol has been added as column wash. Re-centrifuga-tion at $13,000 \times \mathrm{g}$ for 1 minute and discard the collected liquids was done. $250 \mu 1$ were added of room temperature nuclease-free water to the Wizard SV mini-column and incubated for 2 minutes at room temperature (Marko et al, 1982; Boom et al, 1990). Wizard SV minicolumn/elution tube assembly placed into centrifuge and spin at $13,000 \times \mathrm{g}$ for a minute and $250 \mu \mathrm{l}$ of nuclease-free water were added for 2 minute and recentrifuge for 1 minute. Cap the elution tube containing purified genomic DNA and store at $-20^{\circ} \mathrm{C}$. $250 \mu 1$ of nuclease- free water was added to the Wizard SV mini-column and incubated for 2 minutes at room temperature. Wizard SV minicolumn/elution tube assembly placed into the centrifuge and spin at $13,000 \times \mathrm{g}$ for a minute and repeated twice (Soliman et al, 2017).

Primer design for CO1 \& ITS1: Primers were designed using the online server called primer3 (http://bioinfo.ut.ee/primer3-0.4.0/) with specific conditions to give high quality, clear, sharp band and regarding the validation of the designed primer, done by the help of another online server IDT Oligo Analyzer (https://www.idtdna.Com/Primer Quest) for checking the validity and the integrity of the primers and if they have any hairpin form or hetero/homo primer dimer, which revealed a clear and absolute integrity for the structure and validity. CO1 \& ITS1 primers were designed and requested from Macrogen Online Oligo Order System, Korea as follows: COX_F: GAT CCA TAT TTT AAT TTG GTT TCT CCT \& COX_R: CCA GGA AAA GAC CTT AAT ACC C ITS_F: CTA CTC TCA CAC AAG CGA TAC \& ITS_R:
CAA AGT GAC AGT GAC GGA AC.

Cytochrome oxidase subunit and internal transcribed spacer genes from Fasciola sp. were amplified by conventional polymerase chain reaction (PCR) using these specific primer sets. PCR was done in $50 \mu 1$ reaction mixture using $2 \mu 1$ of the genomic DNA extracted from single snail sample (diluted 1:30), 1.5U of Taq DNA polymerase, $50 \mathrm{mM}$ of each dNTPs, $2 \mathrm{mM}$ of $\mathrm{MgCl} 2,2.5 \mu \mathrm{l}$ of PCR reaction buffer (10x) and $0.2 \mu \mathrm{M}$ of each primer (Porta and Enners, 2012). The reaction was performed in T100 gradient thermal cycler of Bio-Rad. PCR mixtures were subjected to an initial denaturation step at $94{ }^{\circ} \mathrm{C}$ for $3 \mathrm{~min}$, followed by 30 cycles of $30 \mathrm{~s}$ at $94^{\circ} \mathrm{C}, 30 \mathrm{~s}$ at $52^{\circ} \mathrm{C}$ to $65^{\circ} \mathrm{C}$ and $60 \mathrm{~s}$ at $72^{\circ} \mathrm{C}$, and a final extension step at $72^{\circ} \mathrm{C}$ for 10 min. An amount of $10 \mu 1$ of each PCR product along with the positive (= PCR mixture including the known DNA sample of Fasciola sp. and negative (= PCR mixture excluding DNA), controls were analyzed by electrophoresis on $2 \%$ agarose gel $(\mathrm{w} / \mathrm{v})$ for approximately 50 minutes at $90 \mathrm{~V}$, and visualized by trans illumination (Jeppson et al, 1979). For standardization of PCR result, laboratory inbred snail soft tissue was used as negative control and infected snail tissue as positive control (in shedding state).

Statistical analysis: Data were tabulated and analyzed. Sensitivity and specificity were calculated using the following: sensitivity $(\%)=\mathrm{TP} /(\mathrm{TP}+\mathrm{FN}) \times 100$ and specificity $(\%)=\mathrm{TN} /(\mathrm{TN}+\mathrm{FP}) \times 100$ (TP: true positive, FN: false negative, TN: true negative $\&$ FP: false positive) (Parikh et al, 2008).

\section{Results}

The shell of L. natalensis is dextral, dark brown in color, fragile, with a wide open funnel. Its whorls range from three to five in number and are spirally coiled. The height of the shell is between $12.5-16 \mathrm{~mm}$ (Fig. 1). Thus, the microscopic methods stated the presence of two types of cercariae. The cercariae were gymnocephalus (fasciolid) cercariae, followed by xiphidio cercariae (Fig. 2). Gymnocephalus cercariae (Fasciolidae) with 
an unforked tail, and length almost as long as the body. Ventral sucker located on midventral surface of body without style in oral sucker and produced by species of family Fasciolidae (Fig. 2, A \& B). Xiphidio cercariae (Plagiorchidea) with an unforked tail; oral sucker with a style, and ventral sucker has the same size of oral sucker and located in the body middle (Fig. 2, C\&D).

Number of gymnocephalus cercariae was higher in Abo-Rawash than xiphidio cercaria $(61 \%)$, in Manshaat Radwan, xiphidio cercaria $(52 \%)$ was higher than gymnocephalus cercariae (Fig. 3).

The present results showed higher infection in Abo-Rawash than in Manshaat Radwan. In Abo-Rawash 56/100(56\%) snails were positive by microscopy compared to 97 (97\%) positive by PCR and $95(95 \%)$ snails were positive by PCR in Manshaat Radwan (Tab. 1). By PCR, all control snails with laboratory infection were positive and control negatives were negative. This meant that PCR sensitivity and specificity were $100 \%$ (no false positive or false negative). The mi- croscopic sensitivity to detect infected snails in Abo- Rawash was 60.8\%; but negative in all uninfected ones (specificity 100\%). In Manshaat Radwan, sensitivity was $51.57 \%$, but negative in all uninfected snails with specificity $100 \%$ (Tab. 2). By comparing the sensitivity of the two methods, the average sensitivity of microscopic method compared to PCR was $56.15 \%$ (Tab. 3).

The present molecular examination showed infection with Fasciola sp. larvae in fieldcollected $L$. natalensis snails from both sites. Notably, the present study used two genes; ITS1 fragment (856bp) and CO1 fragments $(831 \mathrm{bp})$ to prove infection. The optimum annealing temperature of $\mathrm{CO} 1$ primer was $58^{\circ} \mathrm{C}$ and for Fasciola internal transcribed spacer 1 was $56^{\circ} \mathrm{C}$. Agarose gel electrophoresis for both genes showed strong bands at the prospected molecular size: Numbers $4,5 \& 6$ by using ITS 1 primer and $\mathrm{CO} 1$ primer for samples $7,8 \& 9$. The specimen 7 was positive but with faint band by $\mathrm{CO} 1$ primer but while, using ITS1 primer it confirmed by strong band (Fig. 4).

ction in field- collected Lymnaea natalensis

\begin{tabular}{|l|c|c|c|c|c|c|c|}
\hline Localities & Total & \multicolumn{3}{|c|}{ Microscopic examinations } & \multicolumn{3}{c|}{ PCR } \\
\cline { 3 - 8 } & No. & Positive & Negative & Positive \% & Positive & Negative & Positive \% \\
\hline Abo-Rawash & 100 & 56 & 44 & 56 & 97 & 3 & 97 \\
\hline Manshaat Radwan & 100 & 49 & 51 & 49 & 95 & 5 & 95 \\
\hline
\end{tabular}

Table 2: Sensitivity and specificity of microscopy compared to PCR to detect infection in field- collected L. natalensis snails.

\begin{tabular}{|c|c|c|c|c|c|c|}
\hline \multicolumn{3}{|l|}{ Localities } & \multicolumn{2}{|c|}{ PCR } & \multirow[t]{2}{*}{ Sensitivity } & \multirow[t]{2}{*}{ Specificity } \\
\hline & & & Positive & Negative & & \\
\hline \multirow{6}{*}{$\begin{array}{l}\text { Microscopic } \\
\text { examinations }\end{array}$} & \multirow[t]{3}{*}{ Abo-Rawash } & Positive & 56 & 0 & \multirow{3}{*}{60.82} & \multirow{3}{*}{100} \\
\hline & & Negative & 41 & 3 & & \\
\hline & & Total & 97 & 3 & & \\
\hline & \multirow[t]{3}{*}{ Manshaat Radwan } & Positive & 49 & 0 & \multirow[t]{3}{*}{51.57} & \multirow[t]{3}{*}{100} \\
\hline & & Negative & 46 & 5 & & \\
\hline & & Total & 95 & 5 & & \\
\hline
\end{tabular}

Table 3: Average sensitivity of microscopy and PCR to detect infection in field- collected Lymnaea natalensis

\begin{tabular}{|c|c|c|}
\hline Localities & Microscopic examinations & PCR \\
\hline Abo-Rawash & 60.8 & 100 \\
\hline Manshaat Radwan & 51.5 & 100 \\
\hline Average & 56.15 & 100 \\
\hline
\end{tabular}

\section{Discussion}

Morphological examination of the shell of L. natalensis snails revealed that they were thin, dextral, dark brown in color; the shell whorls were ranging from three to five in number and were spirally coiled, its height ranging between 12.5 to $16 \mathrm{~mm}$. This agreed with El-Dafrawy and Taha (2007) they stat- 
ed that the shell was thin, fragile, dextral with height ranged between 10 to $20 \mathrm{~mm}$ and shell whorls ranged from 3 to 5 in number in L. natalensis snails collected from Giza Governorate, which were the most commonest Egyptian species (Ashour et al, 2008) especially in the northern parts of the Nile Delta (El-Dafrawy, 2002).

The present study showed that infection rate in Abo-Rawash was higher than that in Manshaat Radwan village by both methods. The infected snails contained two types of cercariae; gymnocephalus (fasciolid) cercariae and xiphidio cercariae. This agreed with Ashour et al. (2008) who reported that nearly all Egyptian Governorates have fasciolosis, mainly Giza, Fayoum, Damietta, Qaluobia and Kafr El-Sheikh; Gharbia, Dakahlia and Sharkia, and linked the infection to the presence of aquatic plants Lemna gibba and Jussiaea repens. Also, Ahmed and Ramzy (1999); Hussein et al. (2005) and Soliman (2008) stated that both acute and chronic fasciolosis were found in almost all Egyptian Governorates and the infection rates of snails increased during summer months

In the present study, crushing and shedding techniques were used to facilitate microscopic detection of Fasciola sp. in snails compared to molecular dependent ones. The sensitivity of the two methods showed variation of microscopic method compared to PCR by $56.15 \%$. These results agreed with Lambert et al. (2012) and Arafa et al. (2018) who found that the microscopic methods did not give accurate or reliable results, while, PCR assays were highly specific and sensitive, providing useful and practical tools for the epidemiological investigation of Fascio$l a$ in the snail hosts.

Several specific molecular dependent techniques have been developed to detect Fasciola infections in the intermediate host snail and definitive hosts, utilizing various genetic markers, such as ITS regions, and mtDNA, including ND1 and CO1 (Ai et al, 2011; Reaghi et al, 2016). In the present study, the use of ITS1 and CO1 genes con- firmed infection. Discrimination between $F$. hepatica \& $F$. gigantica for the denovo designed primers, CO1 GenBank: AP017707.1 showed a complete homology with $100 \%$ to the hepatica query when using NCBI primer BLAST and ITS primers GenBank: AJ243016.1 revealed incomplete homology with $F$. gigantica while gave complete homology with $F$. hepatica. Agarose gel electrophoresis showed strong bands confirmed infection in both localities. The selected mitochondrial nucleotide sequences of the protein-coding CO1 could be used as an identification gene for the two Fasciola species (Arafa et al, 2018). These results agreed with Ai et al. (2010) who stated that molecular approaches based on DNA sequences of ITS1, ITS2 or the $28 \mathrm{~S}$ ribosomal RNA gene, in combination with mitochondrial gene target were more valuable for the Fasciola sp. identification.

In the present study, the use soft tissue of L. natalensis gave reliable results. However, Arafa et al. (2018) reported that detection of $F$. hepatica by PCR was especially a point of strength by detecting dead and immature Fasciola stages giving missed data.

\section{Conclusion}

PCR is a specific tool to detect Fasciola infection than the traditional methods. Using of ITS1 and mitochondrial CO1genes to detect infection of Fasciola sp. gives reliable and accurate results in field-collected L. natalensis and help in the detection of its prevalence and in the control of this disease.

Compliance with Ethical Standards: All the applicable international, national, and/or institutional guidelines for care and use of animals were followed, but did not deal with human subjects.

Conflict of interest: Authors declared that they never have interest nor received funds.

\section{References}

Ahmed, AH, Ramzy, RMR. 1999: Infection of two lymnaeid snails with Fasciola gigantica in Giza, a field study. Egypt scociety Parasitol J. 29:687-96.

Ai L, Chen M-X, Alasaad S, Elsheikha HM, Li J, et al, 2011: Genetic characterization, spe- 
cies differentiation and detection of Fasciola spp. by molecular approaches. Parasit Vectors 4: 101-6.

Ai, L, Li, C, Elsheikha, HM, Hong, SJ, Chen, JX, et al, 2010: Rapid identification and differentiation of Fasciola hepatica and Fasciola gigantica by a loop-mediated isothermal amplification (LAMP) assay. Vet. Parasitol. 174:22833.

Alba, A, Vázquez, AA, Hernández, H, Sánchez, J, Marcet, R, et al, 2015: A multiplex PCR for the detection of Fasciola hepatica in the intermediate snail host Galba cubensis. Vet. Parasitol. 211:195-200.

Amer, S, Dar, Y, Ichikawa, M, Fukuda, Y, Tada, C, et al, 2011: Identification of Fasciola species isolated from Egypt based on sequence analysis of genomic (ITS1 and ITS2) and mitochondrial (NDI and COI) gene markers. Parasitol. Int. 60:5-12.

Arafa, WM, Hassan, AI, Snousi, SAM, EI-Dakhly, KM, Holman, PJ, et al, 2018: Fasciola hepatica infections in cattle and the freshwater snail Galba truncatula from Dakhla Oasis, Egypt. J. Helminthol. 92:56-63.

Ashour, AA, Mostafa, BB, Taha, HA, Azzam, AMA, 2008: Distribution of natural populations of Lymnaea snails in some Egyptian Governorates and their natural infection with Fasciola. J. Environ. Sci. 16:19-31.

Baran, I, Saray, H, Farzad, K, 2017: Molecular determination of Fasciola spp. isolates from domestic ruminants fecal samples in the Northwest of Iran. Iran J. Parasitol. 12:243-50.

Beesley, NJ, Williams, DJL, Paterson, S, Hodgkinson, J, 2017: Fasciola hepatica demonstrates high levels of genetic diversity, a lack of population structure and high gene flow: possible implications for drug resistance. Int. J. Parasitol. 47:11-20.

Boom, R, Sol, CJ, Salimans, MM, Jansen, CL, Wertheim-van Dillen, PM, et al, 1990: Rapid and simple method for purification of nucleic acids. J. Clin. Microbiol. 28:495-503.

Caron, Y, Lasri, S, Losson, B, 2007: Fasciola hepatica: An assessment on the vectorial capacity of Radix labiata and $R$. balthica commonly found in Belgium. Vet. Parasitol. 149:95-103.

Caron, Y, Martens, K, Lempereur, L, Saegerman, C, Losson, B, 2014: New insight in lymnaeid snails (Mollusca, Gastropoda) as intermediate hosts of Fasciola hepatica (Trematoda, Digenea) in Belgium and Luxembourg. Parasit.
Vectors 7:66-8.

Caron, Y, Rondelaud, D, Losson, B, 2008: The detection and quantification of a digenean infection in the snail host with special emphasis on Fasciola sp. Parasitol. Res. 103:735-8.

Chu, KY, Dawood, IK, 1970: Cercarial production from Biomphalaria alexandrina infected with Schistosoma mansoni. Bull. WHO 42:56972.

Dar, Y, Amer, S, Mercier, A, Courtioux, B, Dreyfuss, G, 2012: Molecular identification of Fasciola spp. (digenea: Fasciolidae) in Egypt. Parasite J. Soc. Française Parasitol. 19:177-9.

Dreyfuss, G, Vignoles, P, Rondelaud, D, 2005: Fasciola hepatica: Epidemiological surveillance of natural watercress beds in central France. Parasitol. Res. 95:278-82.

El-Dafrawy, SM, 2002: Morphological and ecological studies on Lymnaea natalensis the snail vector of Fasciola gigantica in Egypt. J. Egypt. Soc. Parasitol. 32, 2:447-56.

El-Dafrawy, SM, Taha, HA, 2007: Morphological and molecular characterization of Lymnaea natalensis, the snail vector of Fasciola gigantica, in some egyptian governorates. Egypt. J. Zool. 12:347-69.

Hebert, PDN, Ratnasingham, S, deWaard, J R, 2003: Barcoding animal life: cytochrome c oxidase subunit 1 divergences among closely related species. Proceedings Biol Sci 270, 1:S969.

Hussein, A-NA, Khalifa, RMA, 2010: Fascioliasis prevalences among animals and human in Upper Egypt. J. King Saud Univ. Sci. 22:15-9.

Hussein AA, Califa RMA, Mas-Coma S. 2005: Trematode larval stages infecting Radix natalensis (Gastropoda: Lymnaeidae) in Qena Governorate, Egypt, with special reference to fasciolid cercariae. Res. Rev. Parasitol. 66:69-74.

Ichikawa M, Itagaki T. 2010: Discrimination of the ITS1 types of Fasciola spp. based on a PCR-RFLP method. Parasitol. Res. 106:757-61.

Itagaki, T, Kikawa, M, Sakaguchi, K, Shimo, J, Terasaki, K, et al, 2005: Genetic characterization of parthenogenic Fasciola sp. in Japan on the basis of the sequences of ribosomal and mitochondrial DNA. Parasitology 131:679-82.

Jeppson JO, Laurell CB, Franzén B. 1979: Agarose gel electrophoresis. Clin Chem 25.

Kaplan, RM, Dame, JB, Reddy, GR, Courtney, CH, 1995: A repetitive DNA probe for the sensitive detection of Fasciola hepatica infected snails. Int. J. Parasitol. 25:601-10. 
Kaplan, RM, Dame, JB, Reddy, GR, Courtney, CH, 1997: The prevalence of Fasciola hepatica in its snail intermediate host determined by DNA probe assay. Int. J. Parasitol. 27: 1585-93.

Khan, I, Khan, SA, Akbar, N, 2017: Molecular detection of Fasciola hepatica and Toxoplasma gondii in water sources of district Nowshehra. Bull. Environ. Pharmacol. Life Sci. 6:71-9.

Lambert, WJ, Corliss, E, Sha, J, Smalls, J, 2012: Trematode Infections in Littorina littorea on the New Hampshire Coast. Northeast Nat 19:461-74.

Liang, YS, Bruce, JI, Boyd, DA, 1987: Laboratory cultivation of schistosome vector snails and maintenance of schistosome life cycles. J. Basic Appl. Zool. 67, 2: 40-7

Lotfy WM, Brant S V, DeJong RJ, Le TH, Demiaszkiewicz A, et al, 2008. Evolutionary origins, diversification, and biogeography of liver flukes (Digenea, Fasciolidae). Am. J. Trop. Med. Hyg. 79:248-55.

Lotfy WM, Hillyer G V. 2003: Fasciola species in Egypt. Exp. Pathol. Parasitol. 6:9-22.

Magalhães KG, Passos LKJ, Carvalho O dos, S, 2004: Detection of Lymnaea columella infection by Fasciola hepatica through multiplexPCR. Mem. Inst. Oswaldo Cruz 99:421-4.

Marko, MA, Chipperfield, R, Birnboim, HC, 1982: A procedure for the large-scale isolation of highly purified plasmid DNA using alkaline extraction and binding to glass powder. Anal. Biochem. 121:382-7.

Mas-Coma, S, Valero, MA, Bargues, MD, 2009: Lymnaeids and human fascioliasis, with a global overview on disease transmission, epidemiology, evolutionary genetics, molecular epidemiology and control. Adv. Parasitol. 69:41146.

Moema, EBE, King, PH, Baker, C, 2008: Cercariae developing in Lymnaea natalensis Krauss, 1848 collected in the vicinity of Pretoria, Gaut- eng Province, South Africa. Onderstepoort J. Vet. Res. 75:215-23.

Parikh, R, Mathai, A, Parikh, S, Chandra Sekhar, G, Thomas, R, 2008: Understanding and using sensitivity, specificity and predictive values. Indian J. Ophthalmol. 56:45-50.

Periago, MV, Valero, MA, Sayed, MEl, Ashrafi, K, Wakeel, AEl, et al, 2008: First phenotypic description of Fasciola hepatica/Fasciola gigantica intermediate forms from the human endemic area of the Nile Delta, Egypt. Infect. Genet. Evol. 8:51-8.

Porta, AR, Enners, E, 2012: Determining anne-aling temperatures for polymerase chain react-ion. Am. Biol. Teach. 74:256-60.

Reaghi, S, Haghighi, A, Harandi, MF, Spotin, A, Arzamani, K, et al, 2016: Molecular characterization of Fasciola hepatica and phylogenetic analysis based on mitochondrial (nicotiamide adenine dinucleotide dehydrogenase subunit I and cytochrome oxidase subunit I) genes from the North-East of Iran. Vet. World 9:1034-8.

Soliman, MFM. 2008: Epidemiological review of human and animal fascioliasis in Egypt. J. Infect. Dev. Ctries 2:182-9.

Soliman, RH, Ismail, OA, Badr, MS, Nasr, S M. 2017: Resveratrol ameliorates oxidative stress and organ dysfunction in Schistosoma mansoni infected mice. Exp. Parasitol. 174:52-8.

WHO, 2017: Neglected Tropical Diseases. Program. Geneva

Yakhchali, M, Baran, AI, Malekzadeh-Viayeh, R, et al, 2015: Molecular detection of the infection with Fasciola hepatica in field-collected snails of Galba truncatula and Lymnaea stagnalis from West Azarbaijan, Iran. Arch. Razi Inst. 70:195-202.

Zarowiecki, MZ, Huyse, T, Littlewood, DTJ. 2007: Making the most of mitochondrial genomes: Markers for phylogeny, molecular ecology and barcodes in Schistosoma (Platyhelminthes: Digenea). Int. J. Parasitol. 37:140-18.

Fig.1: Dorsal and ventral view of Lymnaea natalensis snails

Explanation of figures

Fig.2: Light micrographs of Gymnocephalus cercariae (A\&B) and Xiphidio cercariae (C\&D) Iodine stain; body (B); oral sucker (OS); stylet (ST); tail (T) and ventral sucker (VS).

Fig.3: Percentage of gymnocephalus and xiphidio cercariae in L. natalensis.

Fig. 4: (2\%) Agarose gel electrophoresis of PCR assay to detect Fasciola sp. in field-collected snails (by specific IRS \&COS primers with a molecular size; $856 \& 831 \mathrm{bp}$, respectively). St =DNA ladder 100bp; 1 negative control; $2 \& 3$ negative infection; $4,5 \& 6$ positive infection (ITS 1 primer); 7, 8 \& 9 positive infection (by CO1 primer), 4, 5 \& 7, 8 samples from Abo-Rawash; 6 \& 9 samples from Manshaat Radwan. 


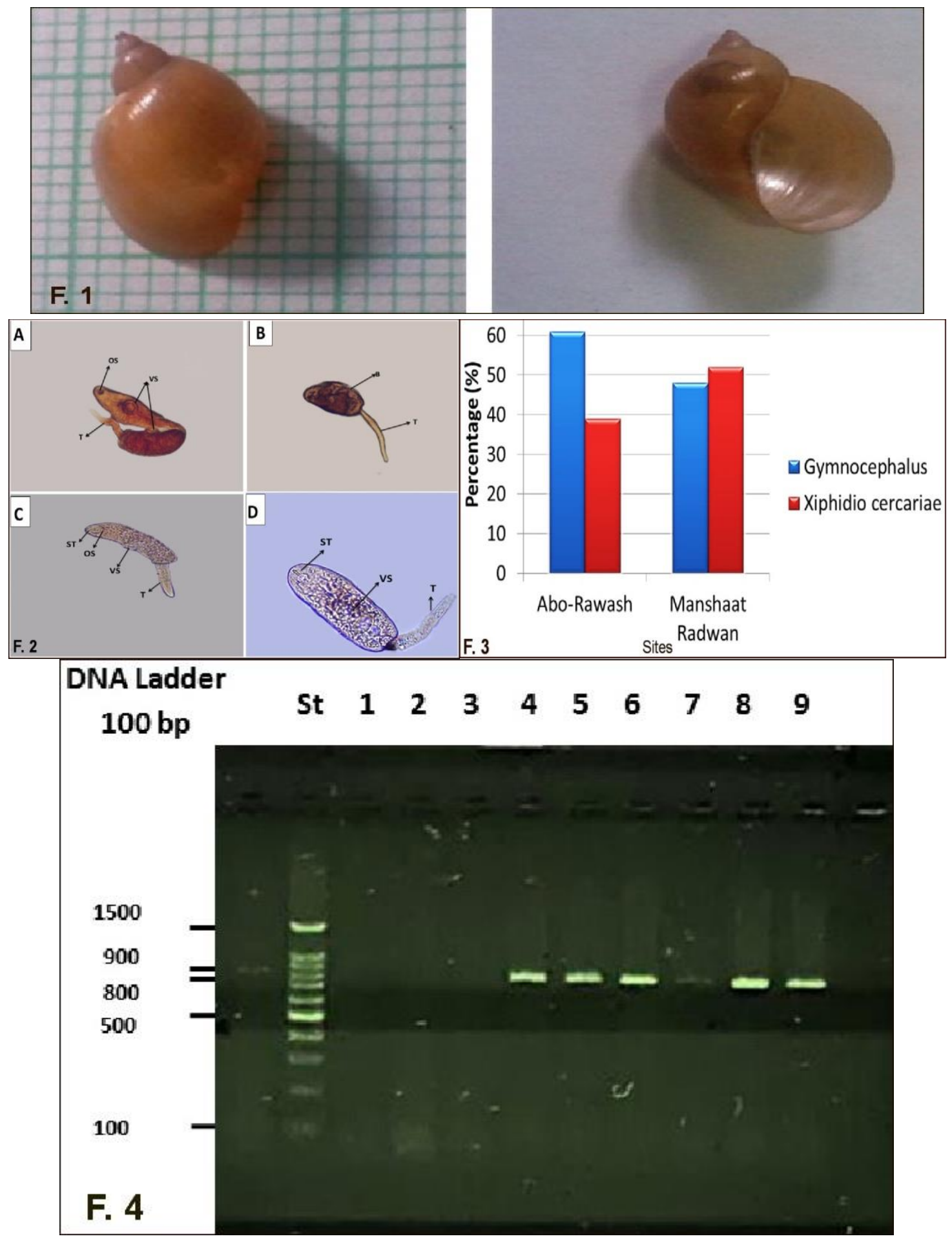

